\title{
Article
}

\section{Multimedia Storytelling in Journalism: Exploring Narrative Techniques in Snow Fall}

\author{
Kobie van Krieken
}

Centre for Language Studies, Radboud University, 6525 HP Nijmegen, The Netherlands; k.vankrieken@let.ru.nl; Tel.: +31-24-361-2347

Received: 23 April 2018; Accepted: 14 May 2018; Published: 16 May 2018

\begin{abstract}
News stories aim to create an immersive reading experience by virtually transporting the audience to the described scenes. In print journalism, this experience is facilitated by text-linguistic narrative techniques, such as detailed scene reconstructions, a chronological event structure, point-of-view writing, and speech and thought reports. The present study examines how these techniques are translated into journalistic multimedia stories and explores how the distinctive features of text, image, video, audio, and graphic animations are exploited to immerse the audience in otherwise distant news events. To that end, a case study of the New York Times multimedia story Snow Fall is carried out. Results show that scenes are vividly reconstructed through a combination of text, image, video, and graphic animation. The story's event structure is expressed in text and picture, while combinations of text, video, and audio are used to represent the events from the viewpoints of news actors. Although text is still central to all narrative techniques, it is complemented with other media formats to create various multimedia combinations, each intensifying the experience of immersion.
\end{abstract}

Keywords: immersion; journalism; multimedia storytelling; narrative; Snow Fall

\section{Introduction}

The concept of storytelling in the domain of journalism is a topic of current and widespread interest, reflected in a growing number of newsrooms embracing narrative formats to deliver their news content [1]. The use of storytelling techniques to report upon news events is, however, by no means a recent innovation. Already in the 18th and 19th century did journalists combine literary and journalistic elements in their writings [2]. The professionalization of journalism in the early 20th century led to a desire for objectivity, along with a desire to refrain from any novel-like aspects. The narrative style of news articles was replaced with a neutral and objective style characterized by the non-chronological inverted pyramid structure in which the most recent information precedes the elaboration of older information [3]. In the 1960s and 1970s, storytelling returned to the American and, somewhat later, European newsrooms under influence of the New Journalism movement. New Journalists employed literary techniques, such as point-of-view writing and scene-by-scene reconstructions, in narrating newsworthy events as well as life in subcultures.

The genre of narrative journalism is nowadays practiced by journalists across the globe [4]. The interest in the genre is often explained by the highly competitive market, characterized by the $24 / 7$ access to free online news, which has forced journalists and editors alike to search for ways to attract the audience's attention and engage them personally $[1,5]$. Telling stories that are both true and enthralling is often seen as an important strategy to achieve these goals. This strategy is central to recent trends in journalism, such as the Slow Journalism movement in which longitudinal and in-depth research forms the basis for high-quality storytelling [6]. Furthermore, the labels of New New Journalism [7] and New, Old Journalism [8] denote contemporary storytelling practices in journalism, 
ranging from the use of an anecdotal lead in a news report to the crafting of full-blown stories that closely resemble literary fiction.

Throughout history, the central aim of journalistic storytelling has remained unchanged: to immerse readers in real world events and situations and excite them "both intellectually and emotionally" [9] (p. 15). The media landscape has changed drastically, however, most notably by the introduction of the Internet in the mid-1990s. Within this new landscape, the resources to produce journalistic stories include no longer only text and image, but also audio, video, and graphic animations. Combining these formats creates multimedia stories. The present study explores how the distinctive features of each of these formats are exploited to immerse the audience in multimedia journalistic stories.

\subsection{Storytelling in Print Journalism}

The main functional communicative difference between non-narrative news articles and news stories (informing vs. immersing the audience) is reflected in stylistic differences. Analytical studies on news stories in print journalism have provided a range of text-linguistic characteristics that are thought to enhance the reader's experience of being immersed into the story (e.g., [10-12]). These characteristics can be roughly divided into three main narrative categories: (1) scene reconstructions; (2) event structures; and (3) viewpoint techniques.

First, whereas straight news reports typically lack descriptive details about the spatiotemporal environment in which the newsworthy events took place, detailed reconstructions of scenes are central to news stories. Consider, for example, the opening scene of a Washington Post story about the aftermath of the 2007 Virginia Tech shooting:

The wind tore through the valley with icy fierceness Monday, as if nature itself were keening over the unthinkable bloodshed. This, after all, was a place of promise and young dreams. Of futures, not funerals. Across the sprawling campus of Virginia Tech, in the shellshocked aftermath of the nation's deadliest mass shooting, the wind whipped through the parking lots now filled with police cruisers, and stung the faces of the few students who hurried past with blank-faced determination. [The Washington Post, 17 April 2007]

Instead of providing newsworthy information, this lead sketches a vivid and detailed scene. Scene reconstructions like this one facilitate readers' imagination of the upcoming events, allowing them to become transported to the story world and virtually observe the events as if they are unfolding in front of their eyes $[13,14]$.

Second, the event structure of news stories tends to deviate from the event structure of non-narrative news articles. The latter type of article is characterized by a so-called inverted pyramid structure in which the most recent information is provided first, followed by older information. This non-chronological ordering of events highlights the most newsworthy event. By contrast, news stories typically follow a dominantly chronological order in which the events are presented according to the order in which they occurred, thus postponing the most newsworthy event until the middle or end of the story. This ordering may contribute to the audience's immersion, as chronologically ordered news stories have been shown to evoke more suspense than non-chronologically ordered news stories [15].

The temporal ordering of events in written stories is signaled by temporal markers (yesterday, later) and verb tense. Whereas the conventional tense in news reporting is the past tense [16], news stories frequently employ the present tense to add a sense of immediacy to the reported events [12,17]. Shifts in verb tense may signal a shift back in time to an earlier event on the time line (flashback), or a shift forward in time to a later event on the time line (flashforward).

Third, the use of viewpoint techniques to describe events from the perspective of news actors is typical for news stories but not for non-narrative news reports [18]. The range of viewpoint techniques varies from the representation of a news actor's speech or thought to the representation of this 
actor's desires, observations, and emotions $[17,19]$. Within the broad category of speech and thought representation, a distinction can be made between different modes of representation. The direct mode renders a news actor's utterance verbatim, e.g., Jake said: "I felt completely overwhelmed". The indirect mode, by contrast, represents utterances in a paraphrasing manner, e.g., Jake said that he felt overwhelmed. The indirect mode is generally considered to be less captivating than the direct mode, in which a news actor's voice is represented in a more expressive and authentic manner. Finally, the free indirect mode combines characteristics of the direct and indirect mode and intertwines the voices of the journalist and the news source [17], e.g., Oh, how he felt overwhelmed right now! The free indirect mode has its origins in literary fiction and is generally assumed to enhance the liveliness of stories by representing the inner voice of characters.

The representation of a news actor's utterances can serve multiple functions. Direct quotations in particular are considered to add both liveliness and truthfulness to journalistic articles [20,21]. In the specific genre of news stories, a relevant distinction can be made between narrative-internal quotations and narrative-external quotations [22]. Narrative-internal quotations represent the speech and thought of news actors during the news events. Their dominant function is therefore to dramatize the story and to intensify the reader's immersion into the story. By contrast, narrative-external quotations represent the utterances of news actors after the news events took place, for instance, at a press conference, court hearing, or interview. Although these quotations also add liveliness to news stories, their dominant function is to demonstrate the truthfulness of the story by showing the audience where, when, and how the journalist gathered information to base the reconstruction of the events on.

Next to speech and thought reports, so-called implicit viewpoint markers can be used to depict the subjective viewpoints of news actors [23,24]. Among these markers are linguistic elements expressing a news actor's cognitive state (e.g., the verbs to realize and to consider), perceptions (e.g., the verbs to see and to notice), and emotions (e.g., the verb to detest or the adjectives scared or delighted). Table 1 provides an overview of the three narrative categories and their text-linguistic features.

Table 1. Text-linguistic features of the three main narrative categories.

\begin{tabular}{|c|c|}
\hline Narrative Category & Text-Linguistic Features \\
\hline (1) Scene reconstructions & $\begin{array}{ll}\text { - } & \text { Location markers } \\
\text { - } & \text { Descriptive detail }\end{array}$ \\
\hline (2) Event structure & $\begin{array}{ll}\text { - } & \text { Temporal markers } \\
\text { - } & \text { Tense }\end{array}$ \\
\hline (3) Viewpoint techniques & 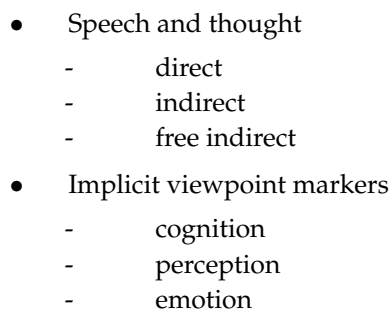 \\
\hline
\end{tabular}

\subsection{Multimedia Storytelling}

From a historical perspective, journalism has always found itself in search of ways to combine multiple media formats as a means to produce compelling stories. In the early 20th century, for example, technological advancements enabled American journalists to experiment with audiovisual formats [25]. Such innovative multimedia productions were deemed necessary to compete with other-highly visually oriented-media, including movies and magazines. 
With the introduction of new media in the early 2000s came both the desire and need for profound convergence: the integration between print and online newsrooms within news organizations [26]. While it was feared that the Internet could usher in the downfall of journalistic storytelling, the rise of new media and technologies has actually introduced new possibilities for journalists to create immersive stories, for example, by producing multimedia stories [27-29]. A multimedia story can be defined as "the presentation of a news story package on a website using two or more media formats, such as (but not limited to) spoken and written word, music, moving and still images, graphic animations, including interactive and hypertextual elements" [30] (p. 140). Multimedia stories have the potential to immerse the audience by offering an encompassing, distraction-free environment [31]. Experiences of immersion can furthermore be elicited by the incorporation of interactive elements [32].

Moreover, for multimedia stories to be successful, it has been argued that the different media formats should complement rather than repeat one another [26]. The present study explores how the discussed narrative techniques—scene reconstructions, event structure, and viewpoint techniques—are expressed in the various media formats employed in journalistic multimedia stories, and to what extent these formats do indeed complement one another in creating an immersive experience.

\section{Materials and Methods}

The New York Times story Snow Fall: The Avalanche at Tunnel Creek [33], published on 20 December 2012, was selected as a case study to explore the narrative techniques employed in multimedia news stories. Snow Fall tells the story of an avalanche that occurred on 19 February 2012 in Tunnel Creek, a section of Stevens Pass in the Cascade Mountains of Washington (U.S.). It killed 3 skiers who were part of a larger group of 16 experienced skiers who had gone on a joint excursion.

Consisting of more than 13,800 words, Snow Fall can be considered a piece of long-form digital journalism. The story is divided into six parts: Tunnel Creek, To the Peak, Descent Begins, Blur of White, Discovery, and Word Spreads. Each part combines text with photographs, videos, audio, and/or graphic animations.

Snow Fall attracted much attention and has already become one of the classic examples of multimedia stories in journalism. It received much critical acclaim for its compelling and innovative combination of multiple media formats. The story has even been argued to have reinvented "the template for digital longform articles" [34] (p. 209); its success is furthermore reflected in the coinage of the verb to snowfall, referring to the adoption of the style and techniques of Snow Fall to cover news stories. Snow Fall won a Peabody Award in 2012, as well as the 2013 Pulitzer Prize in feature writing.

\section{Results}

\subsection{Scene Reconstructions}

The story starts with a full-screen animation of a mountain pass on which the title and author are presented (Figure 1). The animation is dynamic, with snow powder drifting like sand over the surface.

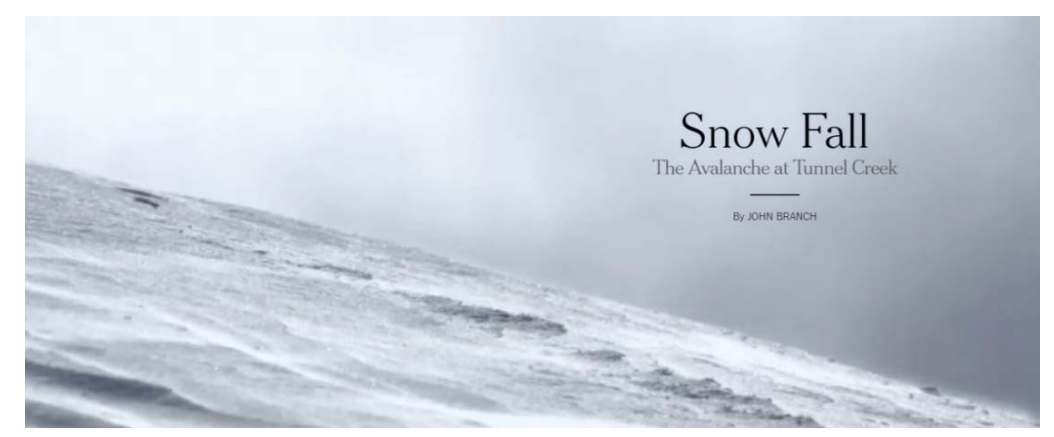

Figure 1. "Title page" of Snow Fall. 
When scrolling below, the animation gradually fades into a white background on which the story's text appears. The setting of the scene is thus expressed visually, allowing detailed information about the scene to be omitted from the first textual part of the story:

The snow burst through the trees with no warning but a last-second whoosh of sound, a two-story wall of white and Chris R.'s piercing cry: "Avalanche! Elyse!"

Five of the story's six parts open with a full-screen picture or animation that represents the setting of the specific story part (cf. Figure 1). One part, The Descent Begins, opens with pictures of the 16 skiers.

After the first episode of the first part of the story, the scene of the action is described in the story's text by means of a general description of the area:

The Cascades are among the craggiest of American mountain ranges, roughly cut, as if carved with a chain saw. In summer, the gray peaks are sprinkled with glaciers. In winter, they are smothered in some of North America's deepest snowpack. [ ... ]

This description contains numerous vivid details that appeal to the audience's imagination (e.g., carved with a chain saw, gray peaks). Upon scrolling down, the white background gradually fades into grey and an animation of the area appears, showing the layout of the mountain pass from a bird's-eye view.

The textual description of Tunnel Creek is accompanied by a video entitled Allure of the Backcountry (see Figure 2). The video shows the area, as well as a skier skiing Tunnel Creek, thereby enrichening the reader's mental image of the story's setting.

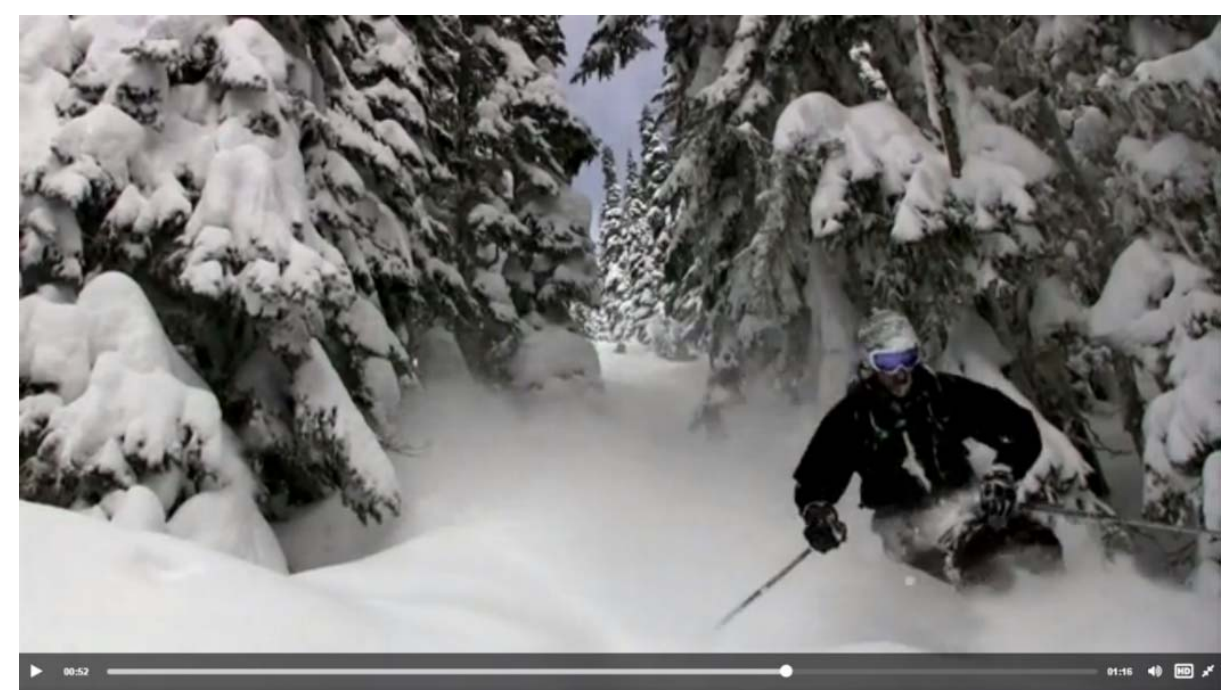

Figure 2. Still from the video Allure of the Backcountry.

Pictures are also used to depict scenes. Figure 3 shows the signs that the group of skiers passed while making their way to the peak of the mountain. 


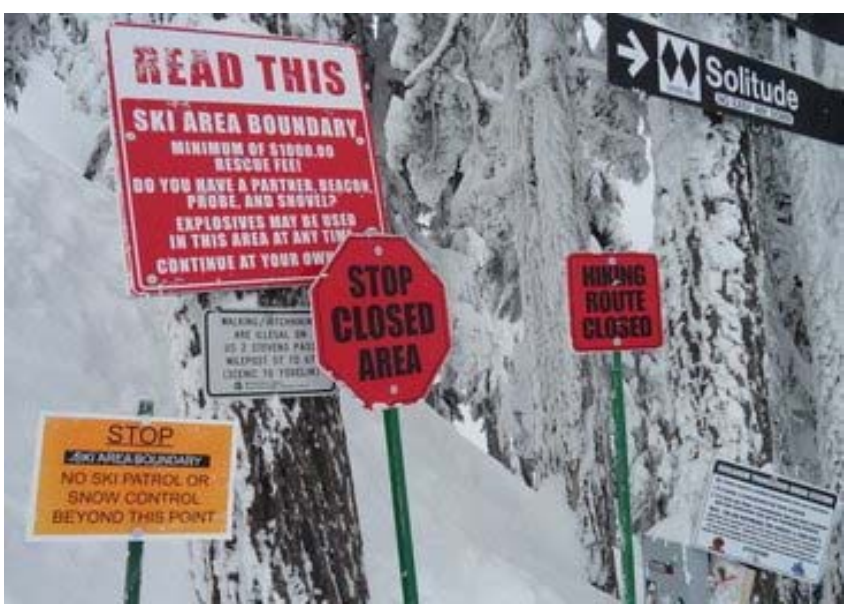

Figure 3. Picture of the warning signs passed by the group of skiers.

Notably, this visual depiction of the scene is supplemented with a textual description of the scene that contains the same information:

"Read this", one sign read in all capital letters. "Ski Area Boundary. Minimum of $\$ 1000.00$ rescue fee! Do you have a partner, beacon, probe and shovel? Explosives may be used in this area at any time. Continue at your own risk".

A smaller sign read: "Stop. Ski Area Boundary. No ski patrol or snow control beyond this point".

In this case, narrative information is thus repeated across modalities. Other instances show how different modalities do not merely repeat but actually complement one another in reconstructing scenes. Part three of the story, Descent Begins, tells how the skiers partnered up before heading down. The story describes, in a successive manner, the trip downwards from the individual perspective of several skiers. Next to the text, a graphic animation is shown that indicates the different routes taken by different duos and individuals. While scrolling down, the route of the skier who is focused on in the text is marked by a moving yellow line.

Figure 4 highlights in yellow the route taken by one of the skiers, Rob C., whose picture and biographical information are shown as well. This graphic animation complements the text, which describes Rob's on-site experiences:

C. went past and cut left. His camera recorded Rudolph and S. whooping their approval as he stopped in a shower of powder, about 40 feet below them.

But just before he stopped, C. was jolted by a weird sensation.

"A little pang, like, ooh, this is a pretty heavy day out here", C. said. "Thing's holding, but I remember having a feeling".

C. stopped above two trees. He nestled close and pushed his right ski tight against them.

The textual narration of the route taken by three other skiers is further complemented by a video entitled Signs of Trouble. This video contains footage from the helmet camera of one of the skiers taped during the fatal trip. It shows the three men discovering and discussing avalanche activity in the area they were skiing.

Finally, one of the most notable elements of Snow Fall is a real-time simulation of the Tunnel Creek avalanche, produced by the Swiss Federal Institute for Snow and Avalanche Research. This graphic simulation starts playing automatically when scrolling down the text of the fourth part of the story, 
Blur of White. It shows the avalanche moving down the mountain from 5300 feet, ripping down trees underway, and finally ending in a debris pile at 3140 feet. The simulation includes information about the avalanche in text (e.g., its speed and approximate weight) and audio effects mimicking the whooshing sounds of the avalanche.

In sum, the story's scenes are reconstructed in multiple media formats: text, videos, pictures, and graphic animations. Whereas textual descriptions invite the audience to actively form a mental image of the scenes, the visual descriptions may fill up or adjust this mental image by showing what these scenes actually look like in general and what they looked like at the very moment the avalanche occurred. Both techniques likely contribute to the audience's immersion, but in slightly different ways: the textual descriptions require audience members to actively engage in imaginative processes, while the visual descriptions allow them to experience the scenes the way in which they were experienced by the news actors.

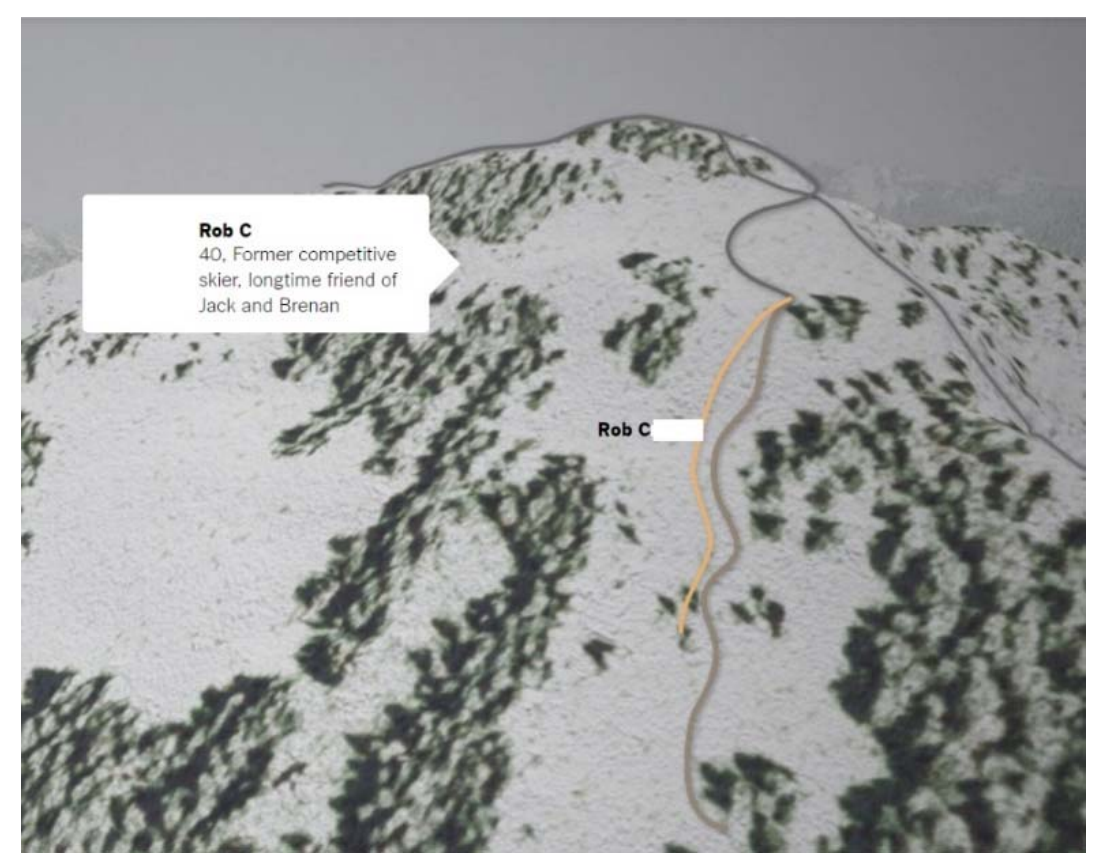

Figure 4. Graphic animation showing the routes taken by the different skiers.

\subsection{Event Structure}

The main story line is told in the past tense. The story starts in medias res with a scene in which one of the skiers gets buried under snow by the avalanche. Then, it moves back in time to the day before, when the plan for the skiing trip was developed and everything was still normal. From that point onwards, the story is narrated in a dominantly chronological order, although several flashbacks are incorporated, including background information about the lives of the skiers. The main story line is also interrupted several times by flashbacks to earlier events on the time line that are not part of the main story plot. In the following example, the temporal adverb In late February 1910 marks a shift in time to an event that has occurred more than 100 years ago.

In late February 1910, ceaseless snowstorms over several days marooned two passenger trains just outside the tunnel's west portal. Before the tracks could be cleared, the trains were buried by what still stands as the nation's deadliest avalanche. It killed 96 people.

This shift in time is also expressed by two old pictures in black and white that show the wreckage after the 1910 avalanche and a group of rescue workers transporting a body, respectively. The narrative time subsequently shifts to the present, as indicated by a shift from the past tense to the present tense and the temporal adverb today: 
To skiers and snowboarders today, Tunnel Creek is a serendipitous junction of place and powder.

The present tense signals that this part of the text provides general information about the area and is not part of the story plot. At other points in the story, such general statements in the present tense are complemented with color pictures of the area.

The following fragment shows how the temporal adverb Earlier that weekend, combined with a shift to the past tense, is used to return to the main story.

Chris R., the effervescent 30-year-old marketing manager for Stevens Pass, knew the preferred route down. Tunnel Creek was his favorite at-work diversion. Earlier that weekend, he mentioned plans for a field trip to Tunnel Creek to a select group of high-powered guests and close friends.

In sum, the story's event structure is expressed in a combination of text and pictures, which complement one another in establishing a coherent time line. Although the main story line is interrupted several times, the dominantly chronological ordering can be expected to foster the audience's immersion into the story by creating suspense [15]. Feelings of suspense might furthermore be elicited by the story's opening, which describes a life-threatening situation without revealing the outcome of that situation.

\subsection{Viewpoint Techniques}

The story is interspersed with speech and thought reports of the news actors. The majority of these reports are narrative-external reports, i.e., reports of utterances made after the news events. The following fragment provides an example.

"Chris was so mad that he had a meeting", H. said. "It was a pow day, and you couldn't tie him to his desk on pow days".

In this fragment, the speaker recalls, from the present, a past emotional state of her husband. Narrative-external reports like this legitimize the narrative reconstruction of the avalanche by demonstrating that the reconstruction is based on statements made after the events, most likely in presence of the journalist. Such reports are captured not only in text, but also in video. At various points in the story, videos are embedded-typically positioned next to the text-that include interview footage of news actors recalling the day of the avalanche. For example, Blur of White, the fourth part of the story, includes a one-minute video showing two skiers talking to an interviewer (not on camera) about their experiences. One of the skiers says:

"I think we were all acting as calm as we could, because we knew that the moment needed composure. But internally, yeah, we were all freaking out".

Narrative-external reports like this explain why the journalist is also capable of depicting the thoughts of news actors during the news events (i.e., narrative-internal reports):

“Tunnel Creek at 11", Jack wrote. "Perfect",

C. thought. "That's just what I wanted to do".

Representing thoughts is a narrative technique generally reserved for narrators of fiction, who have the freedom to invent what their characters are thinking [35]. Journalists do not have this freedom. Upon reading the fragment above, we have to infer that $C$. has shared his experiences with the journalist at a point in time after the day of the avalanche. This inference gains plausibility through the text and videos that include narrative-external reports.

The thoughts of news actors are typically rendered in the direct mode, as in the example above, or the indirect mode, as in the following example: 
At first she thought she would be embarrassed that she had deployed her air bag, that the other expert skiers she was with, more than a dozen of them, would have a good laugh at her panicked overreaction. Seconds later, tumbling uncontrollably inside a ribbon of speeding snow, she was sure this was how she was going to die.

Next to narrative-internal thoughts, the story also displays narrative-internal speech, e.g.,

S. called 911. It was 12:40 p.m.

"I'm reporting an avalanche", she said, breathlessly.

Frantic voices behind her shouted encouragement.

“Come on! You can do it! Come on, buddy! Take a breath!"

The dispatcher said there were "units on scene". S. said they had not arrived and asked if they were coming by helicopter.

"Uh, we do not have a helicopter yet in the area because of the avalanche risk", the dispatcher said.

This fragment represents multiple voices in the direct and indirect mode. The text is accompanied with an audio recording of the 911 call made by S. The audio and the text represent the same information, including emotional details: whereas the text explicitly states that the voices were frantic, indicating the emotional intensity of the events, the audio fragment lets the audience hear the panic in the voices and hence feel the emotional intensity. In this example, the same information is thus encoded in two modalities. Both modalities enhance the audience's immersion into the story at one of its peaks by demonstrating what was being said by the people involved at that specific time. The audio of the 911 call seems to fulfill an additional function, that is, to confirm the truthfulness of the textual narrative-internal quotations.

Such confirmation is also achieved through the embedding of narrative-internal speech in narrative-external speech, e.g.,

"He said: 'It's going to be so good, babe. I'm going to take some folks up to Tunnel Creek,'” H. said.

In this example, a report of an utterance made during the news events (marked by the present tense) is embedded in a report of an utterance made after the news events (marked by the past tense). Note how the direct speech reports are characterized by expressive elements (e.g., babe, folks in the example) that increase their authenticity and liveliness.

The story not only represents news actors' speech and thought, but also their cognitive, emotional, and perceptual states. The following fragment includes several implicit viewpoint markers.

At the upper end of the meadow, more than 100 yards away and out of sight, Elyse S. waited in the silence, unable to move.

She did not know how long she had been frozen there-head pointed downhill, hands sticking out of the snow, face poking through the ice just enough to breathe and see the breaking clouds trailing the weekend's storm.

Her hip ached. Her mind wandered. She wondered who else was caught in the avalanche. She wondered who was left to rescue them.

She felt herself getting colder. 
This fragment describes what Elyse was thinking (her mind wandered; she wondered), seeing (the breaking clouds), and feeling (she felt getting colder) while she was buried under snow and waiting for help. These descriptions invite the audience to adopt the internal viewpoint of Elyse and to imagine what it is like to be buried in snow.

Adopting such an internal viewpoint is also facilitated by videos. The video Allure of the Backcountry shows a skier alternately from an external viewpoint (see Figure 2 above) and an internal viewpoint. Figure 5 shows the internal viewpoint.

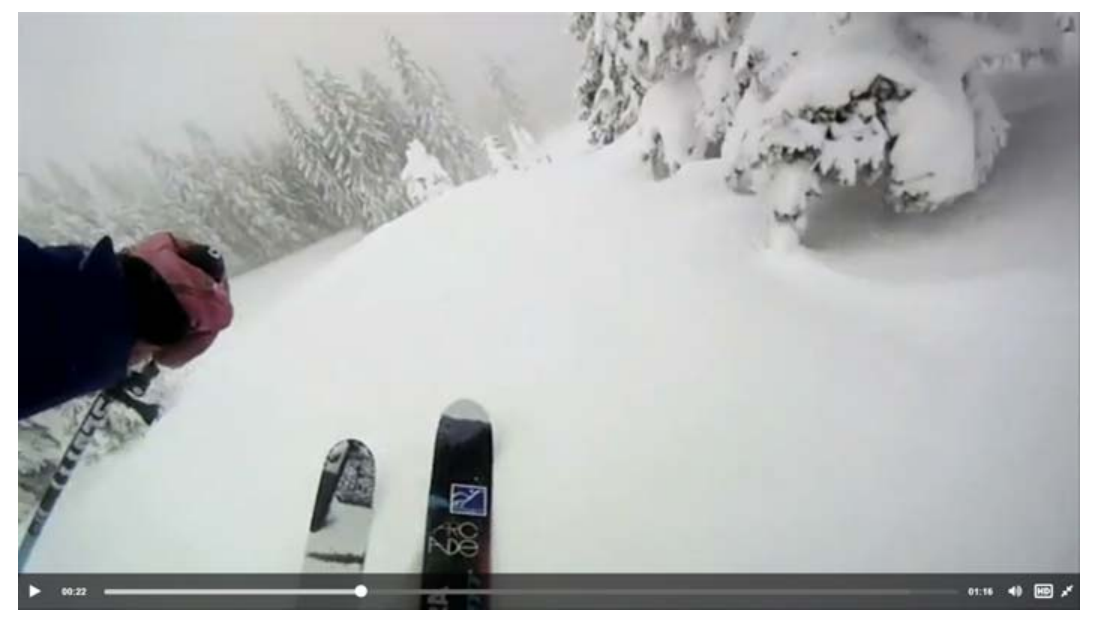

Figure 5. Still from the video Allure of the Backcountry.

This part of the video is filmed by a helmet camera and thus shows what the skier was seeing while skiing down. Although the camera does not literally capture the scenes through the skier's eyes, its position on the helmet does reflect an internal representation. This internal representation enables the audience to virtually experience what it is like to ski Tunnel Creek.

Virtually experiencing the actual avalanche and its aftermath is enhanced by videos made by the helmet cameras of skiers at the time of the avalanche. An example is shown in Figure 6.

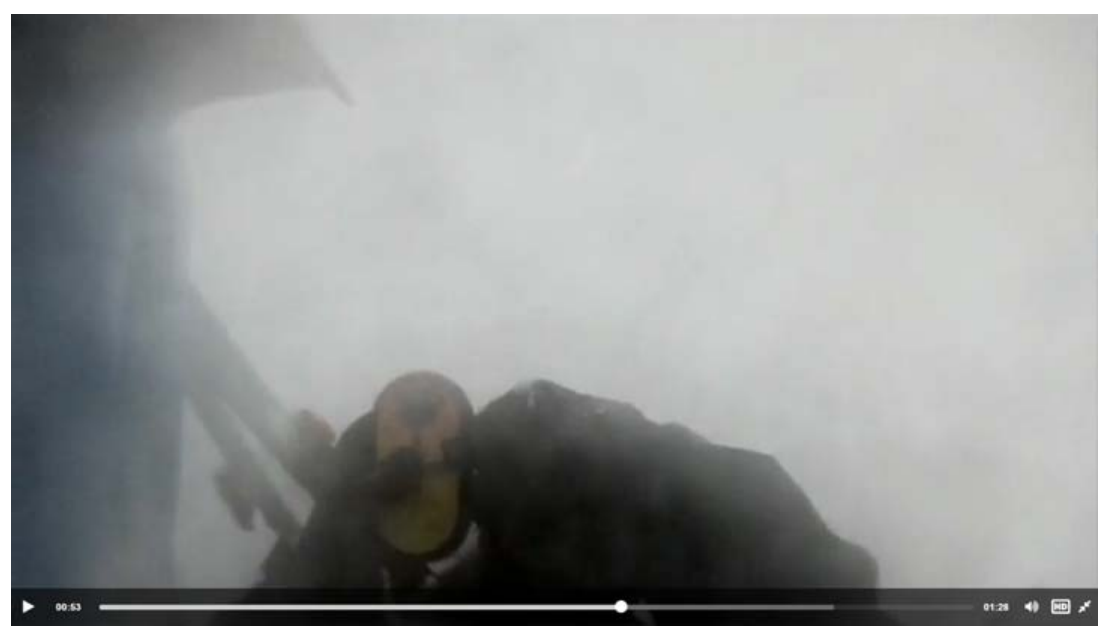

Figure 6. Still from the video "Is that a ski pole?"

This video shows, from the viewpoint of Ron P., how he and Tim C. discover a ski pole sticking out of the snow. It includes narrative-internal dialogue between the two men, e.g.,

"Is that a ski pole?" 
"Where?"

"Right there."

"Yeah, that's a ski pole."

This internal speech is followed by a narrative-external audio fragment in which Tim emotionally reflects on those specific moments, while the video continues, showing Ron taking off his skis, taking out his transceiver and turning it on:

"[ ... ] That's when like, like reality came-came in. Like, I'm crying now, but it was like stone cold like, like 'ah just turn my transceiver on'. Yeah we're getting signals. I'm sitting here getting signals".

This audio fragment depicts what cannot be depicted by the camera: the emotional intensity of the search for survivors and the thoughts crossing Tim's mind.

In sum, a combination of text, video and audio is used to represent the story from the viewpoints of persons involved in the events. Notably, all three media formats represent utterances of these persons in the direct mode. These speech reports are powerful techniques to immerse the audience, as they demonstrate what was being said while the events took place (cf. [20-22]). The reports let the audience both imagine (text) and actually hear (audio and video) the voices of people facing a life-threatening and distressing situation, thus creating the opportunity for a deep engagement with these people.

\section{Discussion}

The goal of this study was to explore how the text-linguistic narrative techniques used in print news stories are translated into multimedia journalistic stories. Results of the case study show that while text is in multimedia stories still central to these techniques, it is complemented with other media formats in different combinations. Table 2 provides an overview of these combinations.

Table 2. Expression of narrative techniques in the media formats employed in Snow Fall.

\begin{tabular}{cccccc}
\hline Narrative Category & Text & Video & Audio & Picture & Graphic \\
\hline (1) Scene reconstructions & $\sqrt{ }$ & $\sqrt{ }$ & & $\sqrt{ }$ & $\sqrt{ }$ \\
(2) Event structure & $\sqrt{ }$ & & & $\sqrt{ }$ & \\
(3) Viewpoint techniques & $\sqrt{ }$ & $\sqrt{ }$ & $\sqrt{ }$ & & \\
\hline
\end{tabular}

Table 2 shows that each narrative category is expressed in a unique combination of media formats. Each of these combinations can be expected to intensify the audience's immersion in distinctive ways. Detailed visual scene reconstructions, for example, enhance the audience's imagination of the story's setting and thus provide them with the opportunity to mentally create a world in which to become immersed. Location markers are used to guide them through this world as the narrative unfolds. These markers are expressed in text, as well as graphic animations. The story's event structure is mainly expressed in text, with an occasional picture reinforcing the narrative time as being present (color picture) or past (black and white picture). Although the story starts in medias res and includes several flashbacks, the main story plot is narrated in a dominantly chronological order, thus increasing feelings of suspense [15].

The representation of events from the viewpoints of the people involved is expressed in text, video, and audio. These representations can be thought of as enhancing the audience's immersion into the story by providing access to what the news actors were feeling, observing, thinking, and saying. Notably, the news actors' speech is captured in all three media formats. Speech reports captured in text, as well reports captured in video, were shown to be either narrative-internal, thus demonstrating 
what was being said during the events, or narrative-external, thus demonstrating what was being said afterwards. Whereas the former type mainly functions to dramatize the story, the latter type fulfills an additional function of confirming the factual status of the story and legitimizing the narrative reconstruction of events [22]. This study thus shows that the legitimizing function of speech reports is not restricted to textual reports but can be fulfilled by video reports as well.

A remaining question is to what extent the identified narrative techniques do indeed enhance the audience's immersion into the story. A previous study showed no differences in immersion between a text-only journalistic story and two different types of multimedia journalistic stories [36]. This result might be explained by the topic of the story used in that study, which was a personal story focusing on a woman's life rather than a specific event or series of events. The lack of a clear story plot might have impeded the immersive potential of the multimedia elements to become realized. Future studies could examine the immersive effects of multimedia stories covering a range of different topics to gain a more comprehensive view on their impact. In addition, future studies could systematically manipulate the expression of the three techniques in the various media format in order to scrutinize which techniques, expressed in which (combination of) media format(s), have the potential to influence the audience's immersion into multimedia stories.

To conclude, this study provides insight into how narrative techniques are employed in multimedia stories so as to create an immersive experience. Text is used for all three categories of narrative techniques-scene reconstructions, event structure, and viewpoint techniques-and is thus not replaced by other media formats. Rather, text is complemented with audio, video, pictures, and graphics - and although narrative information occasionally seems to be repeated across modalities, Snow Fall mainly shows examples of successful integration between the different modalities. Due to its focus on one specific story, a limitation of this study is that these results may not be generalizable to other multimedia stories. Specifically, the use of multimedia elements varies greatly across stories and changes over time. An interesting opportunity for future research lies in a comparison between the 2012 Snow Fall story and a more recent multimedia story. Such a comparison could elucidate the extent to which the functional use of different media formats has evolved over time. In addition, future studies could employ the analytical framework presented in the current study to conduct quantitative corpus analyses. Such analyses could further advance our understanding of narrative techniques in multimedia news stories.

Funding: This research was funded by NWO (the Netherlands Organization for Scientific Research) Grant Number 275-89-038.

Conflicts of Interest: The author declares no conflict of interest.

\section{References}

1. Shim, H. Narrative journalism in the contemporary newsroom: The rise of new paradigm in news format? Nar. Inq. 2014, 24, 77-95. [CrossRef]

2. Hartsock, J.C. A History of American Literary Journalism: The Emergence of a Modern Narrative Form; University of Massachusetts Press: Amherst, MA, USA, 2000; ISBN 9781558492516.

3. Pöttker, H. News and its communicative quality: The inverted pyramid—When and why did it appear? J. Stud. 2014, 4, 501-511. [CrossRef]

4. Keeble, R.L.; Tulloch, J. Global Literary Journalism: Exploring the Journalistic Imagination; Peter Lang Publishing: New York, NY, USA, 2012; ISBN 978433118661.

5. Neveu, E. Revisiting narrative journalism as one of the futures of journalism. J. Stud. 2014, 15, 533-542. [CrossRef]

6. Le Masurier, M. What is Slow Journalism? J. Pract. 2014, 9, 138-152. [CrossRef]

7. Boynton, R. The New New Journalism: Conversations with America's Best Nonfiction Writers on Their Craft; Harvard University Press: Cambridge, MA, USA, 2005; ISBN 9781400033560.

8. Johnston, J.; Graham, C. The new, old journalism. J. Stud. 2012, 13, 517-533. [CrossRef] 
9. Wolfe, T. The new journalism. In The New Journalism: With an Anthology; Wolfe, T., Johnson, E.W., Eds.; Harper \& Row: New York, NY, USA, 1973; pp. 1-52, ISBN 9780060471835.

10. Berning, N. Narrative Means to Journalistic Ends: A Narratological Analysis of Selected Journalistic Reportages; VS Verlag für Sozialwissenschaften: Wiesbaden, Germany, 2011; ISBN 9783531926995.

11. Dingemanse, C.; De Graaf, R. Dutch literary journalism: From pamphlet to newspaper (ca. 1600-1900). In Literary Journalism across the Globe: Journalistic Traditions and Transnational Influences; Bak, J.S., Reynolds, B., Eds.; University of Massachusetts Press: Amherst, MA, USA, 2011; pp. 95-117, ISBN 9781558498761.

12. Van Krieken, K.; Sanders, J.; Hoeken, H. Blended viewpoints, mediated witnesses: A cognitive linguistic approach to news narratives. In Viewpoint and the Fabric of Meaning: Form and Use of Viewpoint Tools across Languages and Modalities; Dancygier, B., Lu, W.-L., Verhagen, A., Eds.; Mouton de Gruyter: Berlin, Germany, 2016; pp. 145-168, ISBN 9783110578577.

13. Van Krieken, K. How reading narratives can improve our fitness to survive: A Mental Simulation Model. Nar. Inq. 2018, 28, 140-161. [CrossRef]

14. Frank, R. "You had to be there" (and they weren't): The problem with reporter reconstructions. J. Mass Med. Ethics 1999, 14, 146-158. [CrossRef]

15. Knobloch, S.; Patzig, G.; Mende, A.-M.; Hastall, M. Affective news effects of discourse structure in narrative suspense, curiosity, and enjoyment while reading news and novels. Commun. Res. 2004, 31, 259-287. [CrossRef]

16. Bell, A. The Language of News Media; Blackwell: Oxford, UK, 1991; ISBN 9780631164357.

17. Sanders, J. Intertwined voices: Journalists' modes of representing source information in journalistic subgenres. Engl. Text Constr. 2010, 3, 226-249. [CrossRef]

18. Van Krieken, K.; Sanders, J.; Hoeken, H. Viewpoint representation in journalistic crime narratives: An analysis of grammatical roles and referential expressions. J. Pragmat. 2015, 88, 220-230. [CrossRef]

19. Van Krieken, K.; Hoeken, H.; Sanders, J. Evoking and measuring identification with narrative characters: A linguistic cues framework. Front. Psychol. 2017, 8, 1-6. [CrossRef] [PubMed]

20. Clark, H.H.; Gerrig, R.J. Quotations as demonstrations. Language 1990, 66, 764-805. [CrossRef]

21. Craig, D. The Ethics of the Story: Using Narrative Techniques Responsibly in Journalism; Rowman \& Littlefield: Lanham, MD, USA, 2006; ISBN 9780742578906.

22. Van Krieken, K.; Sanders, J. Diachronic changes in forms and functions of reported discourse in news narratives. J. Pragmat. 2016, 91, 45-59. [CrossRef]

23. Sanders, J.; Redeker, G. Linguistic perspective in short news stories. Poetics 1993, 22, 69-87. [CrossRef]

24. Sanders, J.; Redeker, G. Perspective and the representation of speech and thought in narrative discourse. In Spaces, Worlds and Grammar; Fauconnier, G., Sweetser, E., Eds.; University of Chicago Press: Chicago, IL, USA, 1996; pp. 290-317, ISBN 9780226239231.

25. Good, K.D. Listening to pictures: Converging media histories and the multimedia newspaper. J. Stud. 2017, 18, 691-709. [CrossRef]

26. Thurman, N.; Lupton, B. Convergence calls: Multimedia storytelling at British news websites. Convergence 2008, 14, 439-455. [CrossRef]

27. Ray, V. News storytelling in a digital landscape. In Journalism: New Challenges; Watt, K.F., Allan, S., Eds.; Centre for Journalism \& Communication Research Bournemouth University: Bournemouth, UK, 2013; pp. 435-443, ISBN 9781408282991.

28. Giles, F.; Hitch, G. Multimedia features as "narra-descriptive" texts: Exploring the relationship between literary journalism and multimedia. Lit. J. Stud. 2017, 9, 74-91.

29. Boczkowski, P.J. The processes of adopting multimedia and interactivity in three online newsrooms. J. Commun. 2004, 54, 197-213. [CrossRef]

30. Deuze, M. What is multimedia journalism? J. Stud. 2004, 5, 139-152. [CrossRef]

31. Hippala, T. The multimodality of digital longform journalism. Digit. J. 2017, 5, 420-442. [CrossRef]

32. Pavlik, J.V. Transformation: Examining the implications of emerging technology for journalism, media and society. Athens J. Mass Media Commun. 2015, 1, 1-16.

33. Snow Fall. Available online: http://www.nytimes.com/projects/2012/snow-fall/index.html\#/?part= tunnel-creek (accessed on 2 April 2018). 
34. Dowling, D.; Vogan, T. Can we "Snowfall" this? Digital longform and the race for the tablet market. Dig. J. 2015, 3, 209-224. [CrossRef]

35. Farner, G. Literary Fiction: The Ways We Read Narrative Literature; Bloomsbury Academic: New York, NY, USA, 2014; ISBN 9781623560249.

36. Pincus, H.; Wojcieszak, M.; Boomgarden, H. Do multimedia matter? Cognitive and affective effects of embedded multimedia journalism. J. Mass Commun. Quart. 2017, 94, 747-771. [CrossRef] 